\title{
A importância da Espiritualidade como construtora do processo de individuação
}

\author{
The importance of Spirituality as an inividuation process constractor
}

\section{La importancia de la Espiritulidad como constructor del proceso individual}

\author{
Lucileide Leila Tavares Vale Alencar ${ }^{1 *}$, Filipe de Menezes Jesuino², Arnislane Nogueira Silva ${ }^{3}$, \\ Michelle Steiner dos Santos ${ }^{4}$
}

Como citar esse artigo. Alencar, LLTV; Jesuíno, FM; Silva, AN; dos Santos, MS. A importância da Espiritualidade como construtora do processo de individuação. Revista Pró-UniverSUS. 2021 Jan./Jun.; 12 (1): 94-99.

\section{Resumo}

Considerando a espiritualidade como importante componente da constituição psicológica dos seres humanos, sendo estudada em vários contextos e por vários pesquisadores, este trabalho investigou possíveis relações da espiritualidade com a saúde, embasando-se na Psicologia Analítica para leitura do fenômeno. O método utilizado na investigação foi a pesquisa bibliográfica e análise teórica de literatura junguiana e não junguiana relacionada à temática. Compreende-se espiritualidade como uma busca pessoal pelo sentido da vida, podendo estar relacionada ao sagrado e ao transcendente. Religião é entendida como um conjunto organizado de crenças, ritos e símbolos que podem ou não promover o contato com o sagrado e o transcendente. Jung não se refere explicitamente ao termo espiritualidade, mas este aparece imbricado em sua obra, especialmente quando ele discorre sobre religião e confissão. Por fim, aborda-se a necessidade de se estudar e discutir a espiritualidade na graduação em psicologia e considerá-la pertinente ao processo psicoterapêutico, sem a adoção de uma postura negligente sobre o fenômeno espiritualidade e processo de individuação.

Palavras-chave: Espiritualidade; Individuação; Psicologia Analítica.

\begin{abstract}
Considering spirituality as an important component of the psychological constitution of human beings, being studied in several contexts and by several researchers, this work investigated possible relations of spirituality with health, based on Analytical Psychology to read the phenomenon. The method used in the research was the bibliographical research and theoretical analysis of Jungian and non - Jungian literature related to the theme. Spirituality is understood as a personal search for the meaning of life, and may be related to the sacred and the transcendent. Religion is understood as an organized set of beliefs, rites and symbols that may or may not promote contact with the sacred and the transcendent. Jung doesn't explicitly refer to the term spirituality, but he appears imbricated in his work, especially when he discusses religion and confession. Finally, we discuss the need to study and discuss spirituality in undergraduate psychology and consider it pertinent to the psychotherapeutic process, without adopting a negligent stance on the phenomenon of spirituality and the process of individuation.

Keywords: Spirituality; Individuation; Analitic Psicology.
\end{abstract}

\section{Resumen}

Considerando la espiritualidad como un componente importante de la constitución psicológica del ser humano, siendo estudiada en diversos contextos y por varios investigadores, este trabajo investigó las posibles relaciones entre espiritualidad y salud, a partir de la Psicología Analítica para la lectura del fenómeno. El método utilizado en la investigación fue la investigación bibliográfica y el análisis teórico de la literatura junguiana y no junguiana relacionada con el tema. La espiritualidad se entiende como una búsqueda personal del sentido de la vida, que puede relacionarse con lo sagrado y lo trascendente. La religión se entiende como un conjunto organizado de creencias, ritos y símbolos que pueden o no promover el contacto con lo sagrado y lo trascendente. Jung no se refiere explícitamente al término espiritualidad, pero aparece entretejido en su trabajo, especialmente cuando habla de religión y confesión. Finalmente, se aborda la necesidad de estudiar y discutir la espiritualidad en psicología de pregrado y considerarla relevante para el proceso psicoterapéutico, sin adoptar una postura negligente sobre el fenómeno de la espiritualidad y el proceso de individuación.

Palabras clave: Espiritualidad; Individuación; Psicología analítica.

Afiliação dos autores: 'Psicóloga. Especialista em Psicanálise Clínica (ABCP). Especialista em Psicologia Analítica (UNICHRISTUS), Fortaleza, Ceará, Brasil. ORCID: https:// orcid.org/0000-0002-7268-796X

${ }^{2}$ Psicólogo. Doutor em Educação pela Universidade Federal do Ceará. Professor do Centro Universitário Pitágoras/CE, Fortaleza, Ceará, Brasil. ORCID: https://orcid.org/0000-00030374-3160

${ }^{3}$ Fisioterapeuta. Mestre em Ensino na Saúde (UECE). Fortaleza, Ceará, Brasil. ORCID: https://orcid.org/0000-0002-0355-1911

${ }_{4}^{4}$ Psicóloga. Pós Doutora em Engenharia do Conhecimento (UFSC). Professora Associada Universidade Federal do Ceará, Fortaleza, Ceará, Brasil. ORCID: https://orcid.org/00000002-6068-4382

* Email de correspondencia: leilalencar@hotmail.com

Recebido em: 11/02/21. Aceito em: 29/04/21. 


\section{Introdução}

O conceito de espiritualidade é composto de muitos sentidos. Na sua raiz esse conceito está ligado ao termo latino "spiritus = espírito" e significa "cheio de espírito ou inspirado.

A Espiritualidade abrange todas as expressões de religiosidade, independentemente de religiões, sendo considerada na atualidade como o conceito superior que aglutina inúmeros fenômenos religiosos ${ }^{1}$.

Entendemos aqui religião na sua essência de espiritualidade, e não a partir de expressões "concretas" atribuídas ao longo da história humana que têm variado significativamente no correr dos tempos ${ }^{2}$.

A Espiritualidade consiste na descoberta de experiência de contato com o eu profundo fascina e dinamiza a vida - Estar meditativo na vida - Arte e o saber de tornar o viver orientado e impregnado pela vivência da transcendência ${ }^{3}$.

É um sistema de crenças que enfoca elementos intangíveis, que transmite vitalidade e significado a eventos da vida. Pode-se citar entre os sistemas de valores subjetivos que impulsionam o desenvolvimento da espiritualidade ${ }^{3}$ os ideais de engrandecimento humano, a psicoterapia baseada na linha transpessoal ou com enfoque existencial, a reza ou prece é a mais universal e comum das intervenções quase $90 \%$ das mulheres e $95 \%$ dos homens fazem prece, $80 \%$ com frequência semanal. A Meditação, prática mais voltada para consciência do corpo, relaxamento físico e mental. A leitura Bíblica ou de outros textos religiosos também pode servir a esse propósito 5 .

Jung $^{2}$ foi um dos estudiosos que mais deu importância ao tema espiritualidade, a compreendendo como uma necessidade arquetípica da psique em direção ao processo de individuação. Ainda segundo o mesmo autor, o centro do Si- mesmo é ocupado pela imago Dei, ou o arquétipo Deus. Este arquétipo possui uma energia poderosa que atrai a si todos os outros e os organiza ao seu redor da mesma forma como o Sol o faz com os planetas. Sem a integração desse arquétipo que se configura como um eixo integrador o ser humano não alcança sua auto realização.

Salienta-se que Jung ${ }^{6}$ não desenvolveu o conceito de espiritualidade e nem se refere a ele explicitamente como fez com diversos conceitos que delimitam a Psicologia Analítica, como por exemplo: Arquétipo, Complexo, Sombra, Persona, Anima e Animus, Si mesmo, Ego, Processo de Individuação, Tipos Psicológicos, entre outros.

Assim sendo é a partir da noção de religiosidade que se deve compreender a espiritualidade na teoria e na psicoterapia junguiana, pois, sendo ela sedimentada na perspectiva arquetípica, entende os eventos existenciais baseados numa ordem simbólica que os relaciona com o processo de individuação e de humanização. Tal conceito caminha por toda sua obra, principalmente quando se refere ao tema religiosidade.

Importante ressaltar que para Jung ${ }^{7}$ a religiosidade enquanto confissão, instituição, dogmas ou práticas espirituais não necessariamente garantem uma vivência religiosa ou espiritual. Para ele religião seria religere, vocábulo latino que significar religar, estabelecer uma conexão profunda que remete ao "numinoso". $\mathrm{Na}$ experiência com o "numinoso" o Eu é tomado por conteúdo do inconsciente o que ocasiona um impacto que vem a ser profundamente transformador da consciência.

Dessa forma, postula-se que os símbolos procuram integrar a totalidade do Si-mesmo, em função de um arquétipo unificador da elaboração simbólica, que Jung denominou de Arquétipo Central. Espiritualidade, na psicologia junguiana é, então, a busca de um relacionamento das vivências com o Arquétipo Central, chamado de Deus nas religiões vivenciado pela experiência do "numinoso"

Qual seria então, a contribuição da Espiritualidade como Construtora do Processo de Individuação? Não seria a vivência do "numinoso" uma experiência transformadora o que entendemos na atualidade por espiritualidade? A partir da perspectiva da Psicologia Analítica, contribuiria a espiritualidade para a construção desse processo?

No sentido de se buscar possíveis respostas para essa conexão, torna-se,necessário entender, na concepção junguiana, o significado de Individuação. Individuação é o conceito central da Psicologia Analítica com o qual se entende genericamente o devir da personalidade, e em particular o processo de transformação contínua de uma individualidade ${ }^{8}$.

O conceito de Individuação baseia-se, em parte, na observação de que as pessoas crescem se desenvolvem geralmente ao longo dos setenta ou oitenta anos que têm de vida nas sociedades ocidentais?.

As pessoas desenvolvem-se sob muitos aspectos ao longo de suas vidas e passam por múltiplas mudanças em muitos níveis. A experiência total de integridade ao longo de uma vida inteira o surgimento do si mesmo na estrutura psicológica e na consciência - é conceituada por Jung ${ }^{9}$ e denominada individuação.

A individuação consiste em desenvolver-se psicologicamente, tal desenvolvimento ocorre em um longo processo, o qual tem como objetivo tornar-se uma personalidade unificada, mas também única, um indivíduo, uma pessoa indivisa e integrada.

Justifica-se essa pesquisa pelo contato com a Doutrina Espírita que ocorreu primeiramente por meio de familiares depois por escolha própria. Em momentos difíceis e incompreensíveis o espiritismo tem auxiliado como força impulsionadora do processo pessoal de individuação ao responder indagações filosóficas sobre 
a vida, propiciar momentos especiais nos trabalhos de assistência social desenvolvidos nos grupos espíritas. A recepção e aplicação de passes, momentos de meditação e oração, fenômenos mediúnicos têm propiciado experiências "numinosas" impactantes e transformadoras, que entendo de enorme relevância para o desenvolvimento da minha espiritualidade.

Ao longo da vivência na Doutrina contou-se com a participação de diversos eventos com profissionais da área de saúde nos quais a temática Psicologia e Espiritualidade são enfocados a partir de várias pesquisas realizadas nessa área.

Uma obra em especial que se tem de referência denominada Série Psicológica do Espírito Joanna de Angelis, psicografada por Divaldo Pereira Franco aborda a temática Junguiana a luz do espírito imortal. Referida obra leva à busca de um maior aprofundamento da Psicologia Analítica através da especialização em curso.

Uma procura pessoal e profissional de reflexão e vivência de uma espiritualidade que venha contribuir com o sentido do percurso pela vida, é sem dúvida, um grande incentivo para buscar um aprofundamento do tema em apreço.

No milênio que ora se inicia, para surpresa de muitos, principalmente no âmbito da academia e da ciência, recrudesce o "renascimento da religião", ou melhor, das religiões ${ }^{2}$.

O Iluminismo que triunfou na parte ocidental do planeta autodeclarando-se como a grande verdade que levaria a compreensão do sentido da realidade encontra-se diante da importância da fé como auxiliar dos enfrentamentos ao longo da vida.

É inegável que essa temática é complexa, gera desconfiança e perplexidade, exigindo por parte dos estudiosos esforços que possam trazer contribuições dentro da perspectiva científica, a fim de que o tema possa ser abordado de forma séria, comprovando, a importância da dimensão espiritual na vida humana.

O século XXI será um século espiritual que valorizará os muitos caminhos espirituais e religiosos da humanidade ou criará novos ${ }^{10}$.

Diante desse contexto, este estudo tem como objetivo realizar uma breve revisão da literatura no tocante a importância da espiritualidade na construção do processo de individuação.

\section{Metodologia}

A metodologia desenvolvida no presente projeto teve como base a pesquisa bibliográfica, no período de janeiro a maio de 2019. Foi realizada uma pesquisa bibliográfica, importante para a construção do referencial teórico, necessário para conhecer o que já foi desenvolvido por outros pesquisadores do tema e para contribuir com a definição dos objetivos do trabalho e construções teóricas.

Este tipo de pesquisa tem sido utilizado com grande frequência em estudos exploratórios ou descritivos ${ }^{11}$. A pesquisa bibliográfica é desenvolvida com base em material já elaborado, constituindo principalmente de livros e artigos científicos. A principal vantagem da pesquisa bibliográfica reside no fato de permitir ao investigador a cobertura de uma gama de fenômenos muito mais ampla do que aquela que poderia pesquisar diretamente. Essa vantagem torna-se particularmente importante quando o problema de pesquisa requer dados muito dispersos pelo espaço ${ }^{11}$.

Este método é realizado a partir de um levantamento de material com dados já analisados, e publicados por meios escritos e eletrônicos, livros artigos científicos, páginas de Web site sobre o tema que desejamos conhecer. Toda investigação científica, independentemente de sua natureza requer uma pesquisa bibliográfica. Ressalte-se que a segurança quanto a seriedade das fontes é outro fator relevante para a realização do trabalho ${ }^{12}$.

Considera-se a pesquisa bibliográfica em síntese como a busca de informações bibliográficas, seleção de documentos que se relacionem com o problema de pesquisa (livros, verbetes de enciclopédias, artigos de revistas de pesquisa, trabalhos de congresso, teses etc.), e o respectivo fichamento das referências para que sejam posteriormente utilizados na identificação das matérias referenciadas ou na bibliografia final ${ }^{13}$.

Os autores selecionados foram Jung ${ }^{1,7,14,15}$, Stein ${ }^{9}$, Pessine $^{2}$, Benzecry ${ }^{16}$. Esse estudo se configurou uma Revisão Bibliográfica, que buscou conhecimentos sobre o tema em livros, artigos científicos, como por exemplo: Psicologia e Religião, Os Arquétipos e o Inconsciente coletivo, A Vida Simbólica, Espiritualidade e Transcendência, Sentimentos, valores e espiritualidade: Um caminho junguiano para o desenvolvimento espiritual, dentre outros.

\section{Resultados e Discussão}

Jung escreveu, em a Interpretação Psicológica do Dogma da Trindade ${ }^{15}$ um texto intitulado Espiritualidade e transcendência. No entanto, quem procura pela palavrachave "espiritualidade" no decorrer de suas obras não encontra muita coisa. A palavra "espiritualidade", como é compreendida na atualidade, não era usual na época de Jung ${ }^{1}$. Religião e religiosidade eram as designações estabelecidas. Apenas recentemente os pesquisadores começaram a considerar as dimensões da espiritualidade separadamente das crenças e dos comportamentos religiosos ${ }^{17}$.

Para Jung as religiões são tão íntimas da alma 
humana por tudo que significam e exprimem, que a psicologia jamais poderia ignorar sua importância. Ele se preocupou em desenvolver uma psicologia da experiência religiosa. $\mathrm{O}$ fato é que a problemática religiosa ocupa na Obra de Jung um lugar central. Importante ressaltar que o que Jung entende por religião não se refere a determinadas confissões. As confissões de fé são formas codificadas e dogmatizadas de experiências religiosas originárias?

Para Jung, religião, como diz o vocábulo latino "religere" seria uma aprimorada e cuidadosa observação do "numinoso", isto é, de algo indecifrável, um mistério "tremendus" aquilo que emite mensagens ${ }^{7}$. Ele sustenta uma compreensão da psique como espaço de experiência do 'numinoso' e que na experiência religiosa o homem se depara com um outro ser, espiritual superpoderoso. Jung $^{1}$ afirma que o Deus nunca falou com o ser humano senão pela alma e a alma o entende e que o ser humano percebe isso como um fato psíquico.

Jung $^{7}$ entende ainda que, no inconsciente, habita uma função religiosa. É recorrente e desempenha uma função de enorme relevância na sociedade humana que ele prefere intitular de "confissão". Não é exatamente uma religião institucionalizada? .

Toda confissão religiosa, por um lado, se funda originalmente na experiência do "numinoso", e, por outro, na pistis, na fidelidade (lealdade), na fé e na confiança em relação a uma determinada experiência de caráter "numinoso" e na mudança de consciência que daí resulta. Um dos exemplos mais frisantes neste sentido, é a conversão de Paulo7.

Entende-se ainda que a experiência religiosa é capaz de propiciar um contato com o "numinoso", experiência passível de nos transformar interiormente produzindo efeitos mediante a mudança das inclinações e antipatias pessoais, valores, e somente essa experiência produzirá efeitos mediante a mudança das inclinações e antipatias pessoais, da concepção de vida e dos valores ${ }^{15}$.O somatório dessas metamorfoses individuais poderá trazer uma solução coletiva. Não estaríamos aqui tratando de Espiritualidade? Experiências religiosas que nos põem em contato com o "numinoso", em princípio, são capazes de nos transformar.

A espiritualidade é concebida como a capacidade de ter fé, amar e perdoar. Inclui a capacidade de se maravilhar, de reverência e gratidão pela vida. É a habilidade de ver o sagrado nos fatos comuns, de sentir a pujança da vida, de ter consciência de uma dimensão transcendente, que leva em consideração o próprio ser, os outros e a natureza da vida ${ }^{18}$.

Em Jung essa experiência religiosa, não é entendida como confissão religiosa, ou como uma religião institucionalizada, mas a que remete a uma experiência "numinosa". Não seria o que na atualidade entendemos como espiritualidade? Na visão junguiana, o desenvolvimento espiritual corresponde ao progressivo tornar-se a Si-mesmo pela integração à consciência do arquétipo da totalidade também conceituado como arquétipo divino $^{16}$.

$\mathrm{O}$ surgimento do Si-mesmo na estrutura psicológica e na consciência na concepção junguiana é conceituada e denominada individuação ${ }^{9}$.

Entrar em contato com o Si-mesmo é uma experiência individual, íntima, que deve ser vivida por cada um em sua história particular. No entanto no processo de individuação não se despreza o fato de que, também, o suporte social, ou seja, o contato com a família, com amigos, professores sejam de crucial importância para esse processo singular ${ }^{19}$.

\section{Individuação}

Jung foi um dos precursores no que se refere aos estudos da duração da vida psicológica contrapondose àqueles que defendem que as mais importantes características do desenvolvimento psicológico ocorrem na infância. Ele viu o desenvolvimento como contínuo repleto de oportunidades de um vir a ser que alcança pessoas de qualquer idade inclusive a meia-idade e a velhice.

O Si-mesmo emerge pouco a pouco sendo representado por Jung como a imagem do sol que surge pela manhã atingindo seu clímax ao meio-dia e mergulhando no seu ocaso à noite. Essas seriam etapas da vida humana que descreveriam seu processo de individuação facilitando o desenvolvimento do Ego. Esse desenvolvimento tem base arquetípica ${ }^{9}$.

Os arquétipos são relativamente autônomos como todos os conteúdos numinosos, não se pode integrá-los simplesmente por meios racionais, mas requerem um processo dialético, isto é, um confronto propriamente dito que muitas vezes é realizado pelo paciente em forma de diálogo ${ }^{20}$.

Quando conscientemente observado e, acompanhado o processo de individuação representa uma confrontação dialética entre os conteúdos do inconsciente e os da consciência onde o símbolo forma a ponte necessária conciliando opostos ${ }^{21}$.

Dessa forma, o processo de individuação é um processo natural, que ocorre em qualquer lugar é aquilo que todo ser é capaz ${ }^{14}$.

O termo individuação remete no sentido do processo que gera um "individuum” psicológico uma unidade indivisível, um todo. Referido termo foi usado por Jung para falar sobre o desenvolvimento psicológico, o qual ele define como um processo que torna uma pessoa integrada visando o desenvolvimento do ego e da persona. O impulso da individuação não é um imperativo biológico, mas sobretudo de natureza psicológica, um fim em $\mathrm{si}^{20}$.

A força propulsora do processo de individuação é 
o si- mesmo e a força impulsionadora é a compensação, tanto na primeira quanto na segunda metade da vida9 .

No que se refere à segunda metade da vida, podemos observar um movimento diferente do que ocorre na primeira. Alguns objetivos pertinentes a primeira metade da vida são questionados. Há por parte do indivíduo uma revisão de valores gerando novos significados. O significado existe alhures e a energia psíquica muda de rumo.

Nessa fase, muitos questionamentos sobre o sentido da vida emergem gerando interrogações que clamam por novos direcionamentos. Urge unificar o ego com o inconsciente, lugar onde habita a vida não vivida da pessoa e seu potencial não realizado. Esse desenvolvimento na segunda metade da vida é o clássico significado junguiano de individuação. Seria o vir-a-ser o que a pessoa já é potencialmente, agora de uma forma mais profunda e mais consciente.

\section{Espiritualidade x Individuação}

A palavra Espiritualidade vem do latim spiritus, que significa "sopro", em referência ao sopro da vida. Define-se também Espiritualidade em termos da capacidade de o indivíduo de ligar-se consigo mesmo, com as outras pessoas e com um ser superior; capacidade para transcender a si mesmo, ao tempo e ao espaço.

Nos dias atuais tem sido dado atenção ao fato de que as pessoas se consideram espiritualizadas sem se voltarem especificamente a nenhuma divindade, a crenças ou mesmo a atividades tradicionalmente associadas a religião. Essas pessoas alcançam uma percepção de conexão espiritual consigo mesmas mediante a integração de recordações do passado, de fatos da vida presente e da projeção do futuro, ou seja, elas tomam consciência de que pertencem a um todo; e também experimentam os efeitos integrativos da espiritualidade em seus relacionamentos.

Nos escritos de Jung ${ }^{16}$ ele reporta a experiência com um analisando Roland $H_{\text {., }}$ que tinha sérios problemas de dependência alcoólica, apresentando diversas recaídas durante a análise, o que levou Jung a dizer a ele que não teria saída em sua dependência "a não ser que tivesse uma experiência espiritual significativa, uma verdadeira conversão". Não estaria Jung se referindo a uma experiência "numinosa"?

A numinosidade, é uma forma de se expressar as experiências em nossas vidas, em que sentimos estarmos mais próximos do que é divino, servindo como influência nas doutrinas e dogmas que as religiões pregam de um modo geral ao longo dos anos ${ }^{21}$. Uma experiência "numinosa" possibilita uma maior integração consigo mesmo. Essa experiência não ocasionaria um impacto no $\mathrm{Eu}$, gerando uma maior integração com o si mesmo, tendo em vista que conteúdo do inconsciente migrariam para a consciência propiciando um sentimento de integração com o si- mesmo ou mesmo uma experiência de individuação? Em assim sendo, não se está diante da tríade: "numinoso" / espiritualidade/ individuação? Um estado não levaria a outro? Ou seja: quando o indivíduo experiencia o "numinoso" na realidade ele estaria vivenciando uma experiência que na atualidade é denominada de espiritualidade. Referida experiência tem consequências no desenvolvimento psicológico do indivíduo aquilo que Jung definiu como sendo individuação um processo que torna uma pessoa integrada visando o desenvolvimento do ego e da persona. O impulso da individuação não é um imperativo biológico, mas sobretudo de natureza psicológica, um fim em si.

Dessa forma, o processo de individuação é um processo natural, que ocorre em qualquer lugar é aquilo que todo ser é capaz, especialmente quando vivencia uma experiência espiritual/ "numinosa".

Por outro lado é importante ressaltar que o impacto de uma experiência "numinosa" também pode acarretar uma desestruturação psíquica ${ }^{20}$. Nessa obra, ele relata a experiência do místico eremita suíço Nicolau de Flüe, denominado pela igreja católica como São Nicolau. Suas visões foram tão terríveis que seu próprio rosto se desfigurou gerando nas pessoas medo e temor. Essa experiência "numinosa" foi desestruturante. Referida visão, apavorante exigiu dele um grande trabalho de assimilação afim de ordenar a estrutura total da alma, restaurando seu equilíbrio abalado. Aqui cabe uma indagação: não teria sido sua fé, suas orações, sua força espiritual, enfim, seus aspectos transcendentais, ferramentas promovedoras de sua restauração psíquica? Aspectos da espiritualidade altamente relevantes construtores da individuação?

\section{Considerações finais}

Jung não se referia a Espiritualidade da forma como a entendemos na atualidade, mas seus escritos sobre psicologia e religião nos levam a fazer uma aproximação entre as experiências "numinosas" propiciadas pela religião não institucional e a religiosidade como uma expressão de Espiritualidade. Para ele uma experiência "numinosa" seria uma experiência transformadora, impactante, propiciadora de questionamentos e reavaliações sobre o sentido da vida através de escolhas mais maduras refletindo uma maior integração da consciência com o si mesmo. A segunda metade da vida é um momento em que o indivíduo necessita de respostas, sentidos e propósitos, sentimentos que podem surgir como fruto de uma experiência "numinosa". Penso que o "numinoso" é uma experiência de espiritualidade que promove enormes contribuições enquanto experiência transformadora e, consequentemente, contribui com o 


\section{processo de individuação.}

\section{Referências}

1. Jung CG, Espiritualidade e Transcedência; seleção de Brigitte Dorst; tradução da introdução de Nélio Scheneider. Petrópolis: Vozes; 2015.

2. Pessine L, Espiritualidade e Arte de Cuidar: O Sentido da Fé para a Saúde. São Paulo: Centro Universitário São Camilo;2010.

3. Dalgalarrondo P, Religião, psicopatologia e Saúde Mental. POA: Artmed; 2008.

4. Saad M, Masiero D, Battistella L, Espiritualidade baseada em evidências. Acta Fisiátrica 2001 8(3):107-112.

5. Shelly JA, The mystery of healing. J Christ Nurs, 2005, 22:6-14

6. Martinez MD, Saúde e Espiritualidade: contribuições da Psicologia Analítica para esse Debate, 2014, Trabalho de conclusão de curso como exigência parcial para a Graduação do Curso de Psicologia da Faculdade de Ciências Humanas e da Saúde da Pontifícia Universidade Católica de São Paulo.

7. Jung CG, Psicologia e Religião. Petrópolis: Vozes; 1978.

8. Jung CG, Cartas de C.G. Jung,(Vol. III, 1956-1961). Petrópolis: Vozes; 2003.

9. Stein M, O Mapa da Alma: Uma introdução. São Paulo: Cultrix, 2006.

10. Boff L, Ethos Mundial: um consenso mínimo entre os humanos. Rio de Janeiro: Sextante; 2003.

11. Gil AC, Métodos e Técnicas de Pesquisa Social. São Paulo: Atlas, 1994.

12. Lopes de Matos KS, Pesquisa Educacional: O prazer de conhecer. Edições Demócrito Rocha. Fortaleza: Uece; 2002.

13. Macedo ND, Iniciação a Pesquisa Bibliográfica. Ed. Unimarco,1994 14. Jung CG, A Vida Simbólica: escritos diversos. Ed. Vozes, Petrópolis. 2013.

15. Jung CG, Explicação psicológica do dogma da Trindade. Petrópolis:Vozes; 1995.

16. Benzecry D, Sentimentos, valores e espiritualidade: um caminho junguiano para o desenvolvimento espiritual. Petrópolis:Vozes; 2016.

17. Goldstein LL, Desenvolvimento do adulto e religiosidade: uma questão de fé. In: Neri AL (org.). Qualidade de vida e idade madura. Campinas, São Paulo: Papirus; 1993.

18. Elkins D, Além da Religião. São Paulo: Pensamento; 1998.

19. Silva AR, Melo O, Mota CP, O Suporte social no processo de individuação em jovens de diferentes configurações familiares. [publicação online]; 2019 [acesso em 15 abr 2019]. Disponível em: http://pepsic.bvsalud. org/pdf/tp/v24n4/v24n4a07.pdf.

20. Jung CG. Os Arquétipos e o Inconsciente Coletivo. Petrópolis:Vozes; 2000.

21. Lascan $\mathrm{D}, \mathrm{O}$ tremendo e o fascinante na psicologia junguiana. [publicação online]; 2019 [acesso em 15 abr 2019]. Disponível em: http:// www.psicologia.pt/artigos/ver_opiniao.php?o-tremendo-e-o-fascinante-napsicologia-junguiana\&codigo. 